\title{
A Study on Residents’ Risk Perception in Abrupt Geological Hazard
}

\author{
Anping Pan \\ College of Architectural and Civil Engineering, Wenzhou University \\ Wenzhou, Zhejiang 325035, P.R. China \\ E-mail: pananping@sohu.com \\ Received 15 February 2012 \\ Accepted 12 March 2012
}

\begin{abstract}
In recent years, there has been an increased frequency and severity of natural disasters, such as typhoons, landslides, earthquakes, etc., now killing and injuring millions of people every year and causing mounting economic losses. The greater tragedy is that many of the losses due to disasters could have been averted. In order to reduce the abrupt geological hazards' casualties effectively in remote mountain areas, local citizens' attitudes of disaster prevention and precaution play an important role and cannot be ignored. This study conducted questionnaire survey to understand their disaster perception and actual evacuation behaviors, and aimed to discuss the special geographic environment and social structure of Qingyuan County in East China's Zhejiang province, investigated the outcrops in areas vulnerable to disasters, and conducts a survey on locals in Shimuxia, Pingtou, Zhangcun, and Tanggen villages. The researcher attempted to understand local people's cognition of and reaction to landslides, mudflows, and other natural disasters as well as hazard perception and coping behaviors. The research results were expected to serve as a reference for the government or local authorities to prepare anti-disaster risk management.
\end{abstract}

Keywords: abrupt geological hazard; risk perception; mountainous area; coping behavior.

\section{Introduction}

Along with global climate changes, environmental degradation and its own economic takeoff and population explosion, people and the environment are increasingly suffering from the effects of natural disasters. Although there are some engineering methods to prevent natural disasters, there is no perfect method because natural phenomena often exceed the assumption. China is one of the most geological and meteorological disaster prone countries of the world. The abrupt geological disasters such as rock avalanches, landslide, mud-rock flows, etc. can be easily triggered by a variety of external stimulus, such as intense rainfall, earthquake shaking, water level change, storm waves or rapid stream erosion. The disasters lead to destroying roads, ruining residential area, blocking rivers and resulting in enormous property damage in terms of both direct and indirect costs each year. There is growing scientific evidence that risks due to geological disasters have become increasingly, especially in mountainous regions. Because young people leave mountainous areas and go to towns, declining population and aging become serious problems in mountains. And destruction of mountain forests or inappropriate farming practices can accelerate erosion and expose land to the risk of landslides, floods and avalanches. When a disaster happens in such areas, the damage would be serious due to the barrier for delivering rescues resources and ineffectively dissemination of disaster related information. People would be besieged in the villages and couldn't evacuate to safe places, and saving goods also couldn't transport to the villages, rescue efforts would be hampered by bad weather, treacherous

\footnotetext{
${ }^{*}$ This material is based upon work funded by Zhejiang Provincial Natural Science Foundation of China under Grant No. Y5110022
} 
mountain terrain. This implicates that prevention measures are barely carried out and people in emergency situations can't be rescued due to insufficient capacities in basic rescue and to the absence of a mountain rescue system.

Mountainous areas in East China's Zhejiang Province typically have steep topographies, and are therefore vulnerable to typhoons, landslides and debris flows. For instance, in 2004, Typhoon Rananim caused countless casualties to the Longxi Township, Yueqing City; and Typhoon Saomai in 2006 also caused numerous causalities and landslides. Thereafter, residents in hillside areas began paying attention to natural disasters. In response to the public's growing concerns over landslides and debris flows, the national governments at all levels have launched many programs aimed at disaster mitigation. Although great progresses have been reached in the field of abrupt geological hazard prediction and warning, many shortages still exist now, such as: the operation of excavation has not taken into consideration the willingness and behavior of the excavated. The lack of knowledge attributed from the studies referring to the recognition of risk, needs, and behavioral pattern of evacuees make the decisions made by authorities sometimes turn aside from the reality. Under this circumstance, the government and disaster managers need to study the residents' population characteristics and their behavior in emergencies.

When it comes to conceptualizing the idea of disaster prevention and rescue, people often emphasize on the rescuing and rebuilding after the disaster. Experts on disaster relief have increasingly called for a greater emphasis on prevention as opposed to relief. The government as well as public bodies have also reinforced measures and policies to prevent disasters. In recent years, The Chinese governments at all levels have made great efforts in undertaking disasterreduction projects, improving disaster early warning and emergency response, enhancing sci-tech support, strengthening personnel training and disaster reduction work in communities. Disaster risk management needs to be motivated and based within governmental responsibilities, but its success cannot be accomplished without the benefits of widespread decision-making and the participation of many others. The public awareness of risk is therefore a necessary condition to engage in disaster risk reduction. People are more vulnerable when they are not aware of the hazards that pose a threat to their lives and assets. Levels of risk awareness depend largely upon the quantity and quality of available information and on the difference in people's perceptions of risk.

Risk perception among others is an important determinant of the behavior towards risks, e.g. for the decision to take preventive measures. If risk perception of people living in risk prone areas is known, effective information strategies on protective measures can be designed. Since G.F. White's (1945) pioneering work, risk perception has been the central focus for many social scientists interested in natural hazard and disaster studies. The choice of adjustment basically depends on how people perceive threats and the associated risks for themselves. Although risk perception is not sufficient for predicting successful evacuation, it is an important variable in determining the effectiveness of proposed evacuation projects.

There is a diverse literature on risk perceptions and coping capacities that has significantly contributed to our understanding of how population's act and cope faced with geological hazard-related risks in the last decades, for example, Geographer R. Kates (1971) first lists a number of factors that may affect risk perception and develop this into a human ecological model of human adjustment to natural hazards. First are the nature and features of the natural hazard involved including its magnitude, duration, frequency and temporal spacing. Second are the frequency and intensity of personal experience of past, similar, events. Finally, personality actors like fate control, different views of Nature and the tolerance of dissonancecreating information are significant. And these factors are independent from the socio-economic environment. Mileti (1993) underlines that people respond to a risk or hazard in ways consistent to their perception of that risk. It is their perception that influences behavior or action. Lindell and Perry (1993) argue that understanding public perception of natural hazards is necessary in order to impact hazard preparedness, and can be a problem because residents of at risk areas often have inaccurate beliefs about the hazard agent and its impacts, are unaware of available adjustments, and may have erroneous beliefs about the effectiveness of the adjustments of which they are aware. Janis and Mann (1977) prove that adaptive actions are motivated by 
awareness of the hazard, knowledge of how it can affect the community, and feelings of personal vulnerability to the potential consequences. In china, there are relatively few researches on perception of risk and short of thorough and systematic research at present. Zhouqi et al. (2008) take Shangbaiyun Village, Taibai County as example, and studies on the natural disaster perception of village in a mountainous area. Sunlili et al. (2010) explore factors of influence on refuge behavior of mountainous area masses from typhoon disaster.

Hence, to know the hazard cognition of the residents in remote mountain area is conducive to the effective development of disaster reduction education. This paper will use methods from some disaster management theories and literatures to study the disaster management problems. Residents' attention to geological hazards, awareness of disaster prevention, disaster theoretical knowledge, knowledge of emergency behavior and views on disaster risk reduction education are studied through questionnaire investigation. The purpose of this study is to provide the authorities concerned with results and suggestions which can be helpful in the future planning.

\section{Study Areas}

\subsection{Qingyuan County background}

Qingyuan County is located in Southwest Zhejiang Province near the border between Zhejiang and Fujian. It lies between $27^{\circ} 25^{\prime}$ and $27^{\circ} 51^{\prime}$ north latitude and $118^{\circ} 50^{\prime}$ and $119^{\circ} 30^{\prime}$ east longitude (Fig.1). It faces Longquan City and Jingning County on the north. With an extensive hinterland in the rear, it shares borders with Fujian Province on three directions of east, south and west. The County is $67 \mathrm{~km}$ across from east to west and about $49 \mathrm{~km}$ from north to south, and about $1898 \mathrm{~km} 2$ in the area. Qingyuan is a key forestry county with rich forest resources. The county is composed of $85.5 \%$ mountains, $1.2 \%$ surface water, $5.6 \%$ farmlands, and $7.7 \%$ roads, villages and towns. It has high, clustered mountains to the east, north and west, with the altitudes ranging from $330 \mathrm{~m}$ to $1800 \mathrm{~m}$. The highest peak, Mount Baishanzu ranks second highest peak in Zhejiang Province with an altitude of 1,856.7 meters. It has a low-lying basin in its central-southern part, and capital city in its center.

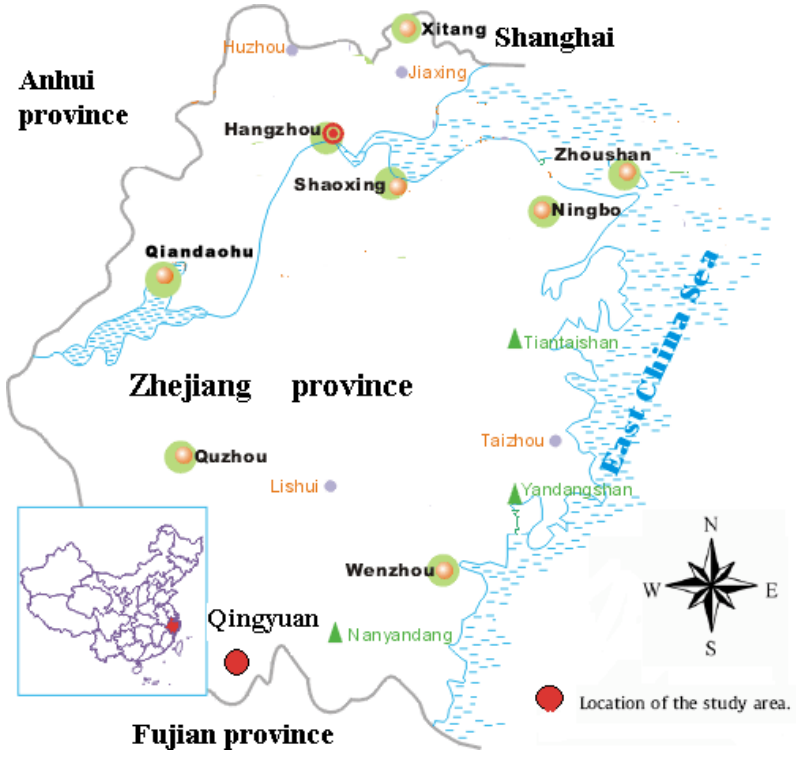

Fig. 1. Location of the case study area

Qingyuan County has seven towns, thirteen countryside areas, five residential areas and 344 administrative villages and the permanent population under its jurisdiction reached 203.6 thousand by the end of 2010 . The County has a subtropical monsoon climate with four distinct seasons, with an annual mean temperature of $17.6^{\circ} \mathrm{C}$, and the mean annual precipitation is about $1721.3 \mathrm{~mm}$. From May to November, known as the typhoon season, the rain is brought by the violent whirl wind and that consists about $60 \%$ of the total rainfall. It has a frostless period of 245 days per year.

\subsection{Current situation of geological disasters in Qingyuan County}

Qingyuan is a main geological hazard area in Zhejiang province where geological environment is complex and geo-hazard occur continually. The types of geological disasters are many and the distribution scope of disasters is wide. The main ones are rock fall, landslide, debris flow, land collapse. In recent years, affected by extreme weather, earthquakes, engineering, construction and other factors, frequent geological disturbances caused serious damage to people's lives and property. For instance, on August 11, 2006, Typhoons Saomai made landfall with extremely strong wind and large amounts of rainfall, and therefore the rain-triggered debris flows hit Shimuxia Village of Qingyuan County 
burying about 20 people, leading to direct economic losses of more than 5 million yuan (Fig.2).

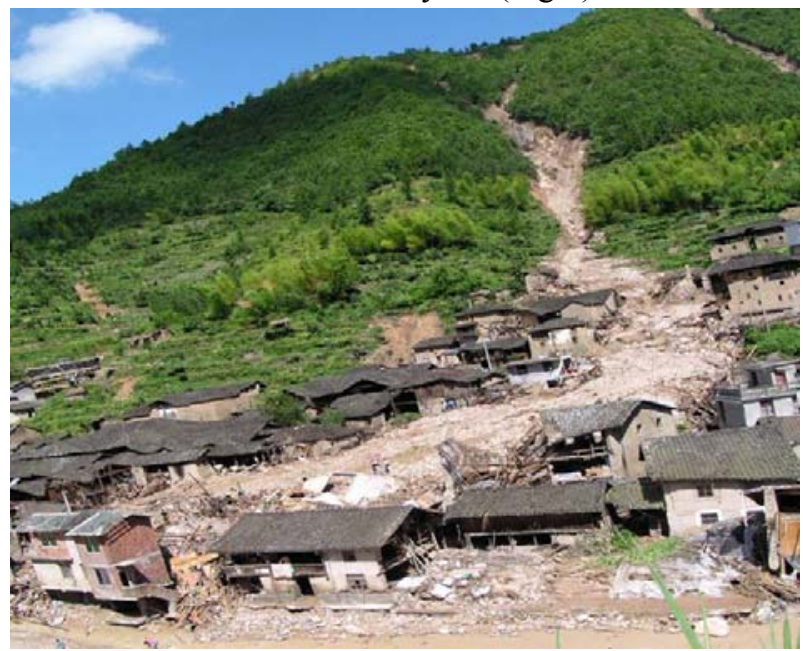

Fig. 2. The scene of a debris flows at Shimuxia Village in Qingyuan County on August 11, 2006

Based on field survey, the distribution of geological hazards, geomorphology and geological structure, disaster- point density, disaster risk as well as the relationship between geological disasters and human activities were precisely investigated, in 2011, the Qingyuan government confirmed 168 geological hazard places as disasters monitoring area, which threaten the security of 17992 peoples and may bring about losses of nearing 100 million yuan (Fig.3).

\section{Methodology}

People's beliefs about geological hazards and what can be done to manage their consequences can be formed and maintained in several ways. One relates to hazard experience. Another involves informing people, usually via public hazard education programs, about the hazards they face and the measures and actions they can adopt to mitigate their risk. In order to study the perception of geological risks and its influencing factors, a survey was conducted among persons living in affected areas of Qingyuan County.

\subsection{Questionnaire design and survey procedure}

The questionnaire is designed to obtain information on the public's impressions of (1) what geological hazards (i.e. the mudflow or landslide) are and where they occur, (2) the threat from future geological hazards, and

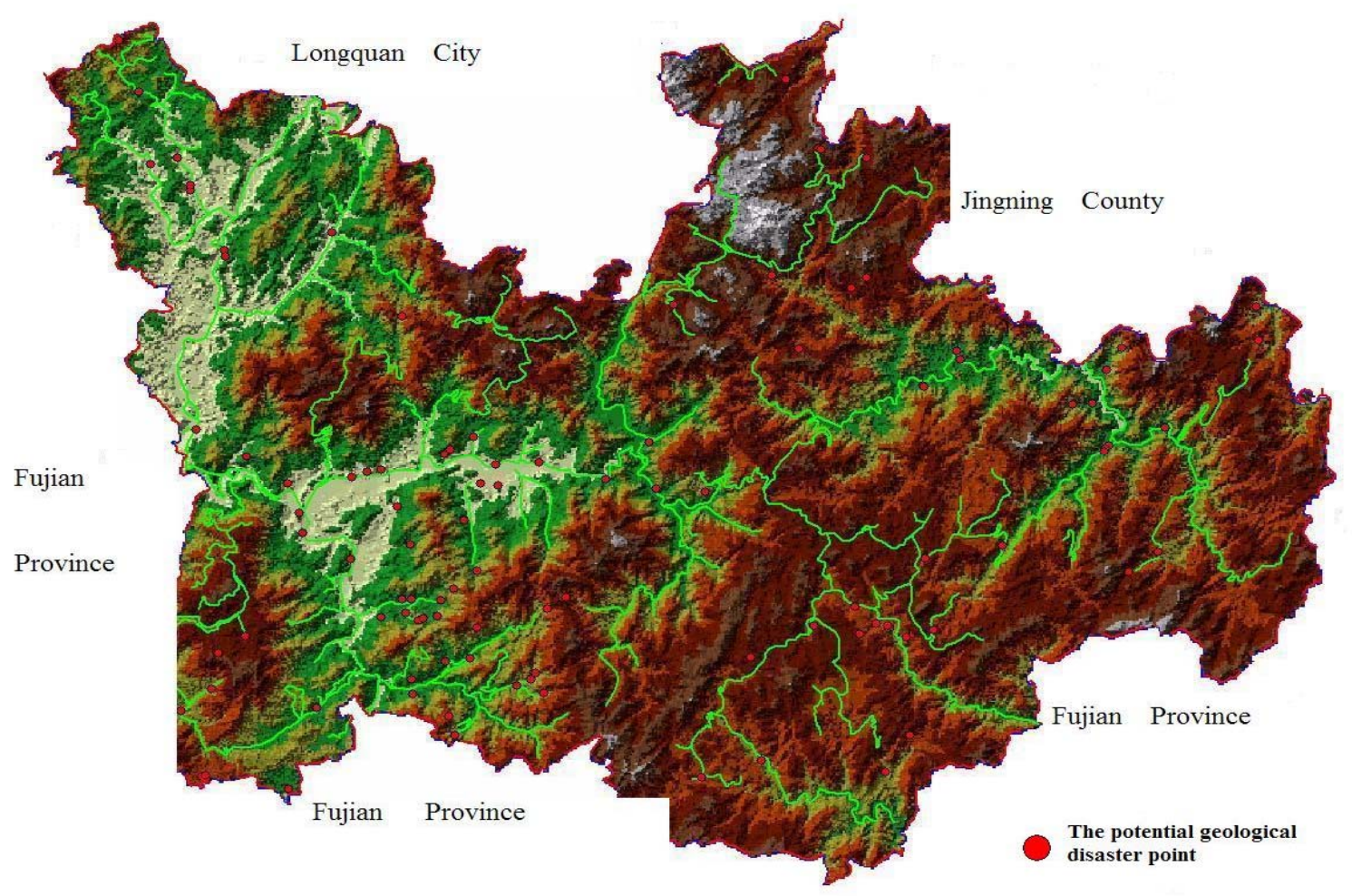

Fig. 3. Distribution of potential geological disaster points in Qingyua County 
(3) how to respond in case of an emergency.

The questionnaire had three categories of items: demographic background, risk perception and coping behaviors. Some questions were designed to give information on demography and the socio-economic context in which respondents live (e.g., age group, gender, profession, etc.). Some questions were designed to evaluate the respondent's knowledge of geological hazards; understand the respondents level of and views on, hazard education; knowledge of any existing emergency plans; communication strategies; and general level of preparedness and responsibility in the event of a crisis. In some questions, respondents were allowed to select a single answer, while in others, they could select one or more alternatives (see Section 4).

In July 2011, we conducted a survey in which we interviewed a range of people to determine their general level of awareness and knowledge of geological hazards and risks in affected areas of Qingyuan County. The research team was composed of 10 students trained in the technique of questionnaires and working under the close supervision of the author. We distributed the questionnaire to 300 inhabitants living in Shimuxia, Pingtou, Zhangcun, and Tanggen villages in the areas. A number of criteria were used to select respondents for the survey. The sample was stratified with respect to age, gender, education, profession and geological disasters experience. The local people responded based on their understanding which is very much related to natural disasters and disaster prevention. All respondents were required to complete the questionnaire on the spot, eliminating any chance to information from other people or sources. The overall response rate was $90 \%$, of which 255 questionnaires were properly completed, for a completion rate of $85 \%$. The main reason for refusal to participate seemed to be lack of available time (it took approximately 20 minutes to fill out the questionnaire).

\subsection{Sample characteristics}

The final sample consisted of 255 responds (145 females and 110 males). The age of the respondents ranged from 14 to 75 year, results for the total sample (255) were divided into three different age groups: 23(9.0\%) participants were 14 to 17 years old (minors group), $197(77.3 \%)$ were 18 to 65 years old (adults group), and 35 (13.7\%) participants were older than 65(elderly group). With regard to the highest level of education completed, $36.5 \%(\mathrm{n}=93)$ participants had not completed secondary education, while $46.3 \%(n=118)$ were junior high school graduates, $11.4 \%(n=29)$ were high school graduates, and 5.9\% $(\mathrm{n}=15)$ had some university degree. Most of respondents $(78.4 \%, n=200)$ were farmers, the student population (which include high school, university and recent unemployed graduates) constituted $7.5 \% \quad(n=19)$, the highly scholarized population (state officials, teachers, doctors, etc.) constituted $4.7 \%(\mathrm{n}=12)$, and those in unskilled occupations (drivers, traders, etc.) constituted the remaining $9.4 \%(n=24)$.

Most of the respondents $(n=211,82.7 \%)$ reported at least one direct involvement of geological hazards (i.e. the mudflow or landslide) in the past, and their lives were temporarily influenced in a negative way by geological disasters; for instance, their children were unable to go to school because their schools were damaged by the landslides. $58.8 \%$ declared that their relatives were injured or their assets were damaged.

\subsection{Scoring rules}

We recoded these variables as follows:

- Socio-demographic and experiential characteristics: gender $\quad($ male $=1$, female $=0)$; age groups of participants (minors $=0$, adults $=1$, elderly $=2$ ); level of education (not completed secondary education $=1$, junior high school $=2$, high school $=3$, university degree $=4$ ); having suffered geological hazard in the past (yes $=1$, no $=0$ ); having received information about geological risks $(\mathrm{yes}=1, \mathrm{no}=0)$; having participated in disaster preparedness drill (yes $=1$, no=0).

- Respondent's responses are presented based on the different aspects of risk perception tested. For the purpose of brevity, most of the results were summed as percentages. It should be noted that for some questions, responses may total more than $100 \%$ since respondents were permitted to select several answers. And the others, Items were related to overall feelings of self-worth/self-acceptance. responses were measured on a Likert five-point scale ranging from 1 to 5 , with higher numbers indicating higher levels of likelihood, severity, worry, trust, etc.. And the format of a typical fivelevel Likert item, ranging from 'strongly agree' 
( score $=5)$ to 'strongly disagree' $($ score $=1)$. So the point 3 on the scale marked a neutral position.

\subsection{Questionnaire analysis}

The collected questionnaire forms were analyzed by using simple sorting procedures and basic mathematics and statistics methods. Most of the calculations were done in the computer using SPSS 13 and Microsoft Excel software. Statistical tests were conducted on a range of risk-related variables, with the significance level determined at $\mathrm{p}=0.05$.

\section{Results and Discussions}

The results discussed in this section are based on the 255 questionnaires forms from the residents of sampling areas. The findings from the questionnaires were analyzed part by part. The detailed results are shown below followed by discussions.

\subsection{Hazard salience}

Qingyuan County is stricken by a great variety of natural hazards; earthquakes, landslides, mudflows, floods, etc. How people respond to a natural disaster occurring or in preparation for another is often a function of their culturally-derived perception from previous training, education, and experiences.

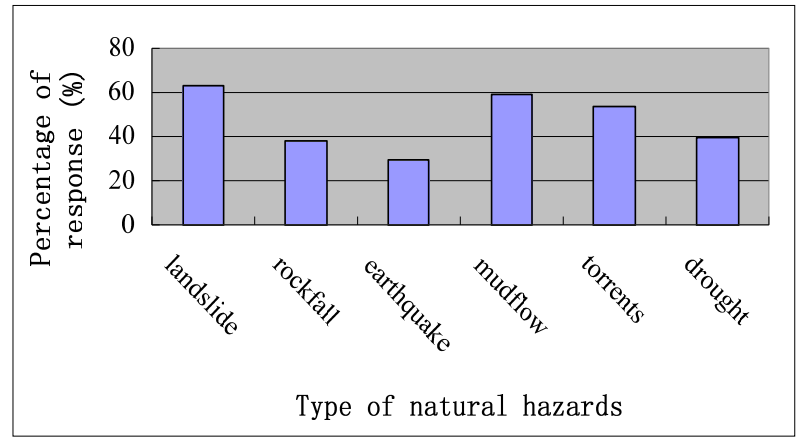

Fig. 4. Respondent's perception of natural hazards which commonly affect their villages

In order to determine the extent to which natural hazards are on the minds of the residents, one of the very first questions on the questionnaire asked them to list the likely natural hazards to affect their living villages (Multiple choices). As shown in Fig. 4, the results indicated that natural hazards were foremost in the minds of residents: $62.7 \% \quad(n=160)$ indicated landslides; 59.2\% $(\mathrm{n}=151)$ indicated mudflows; 53.3\% $(n=136)$ indicated torrents; $53.3 \%(n=100)$ indicated droughts. As for the other natural hazards, rock fall and earthquakes respectively represented $37.6 \%(n=96)$ and $29 \%$ ( $n=74)$. In studied locations, respondents were emphasizing their own experience compared to other risks or disaster they did not experience themselves, but they got to know through Medias like television, etc.

In the investigation, almost all respondents, more or less, knew something about natural hazard. But only thirtyone percent of them took the initiative to learn while the others just received the relative knowledge passively. And the level of people's knowledge about disasters reflects their abilities to deal with disaster information and further shapes the awareness and behaviors of disaster prevention and reduction.

\subsection{Geological hazard risk}

Once a hazardous condition is recognized it must be evaluated to determine the threat or risk it presents. In order to stimulate the imagination of the interviewees and to highlight the lack of risk communication, the respondents were asked what they thought the geological hazards (i.e. the mudflows or landslides) could do to them around the region.

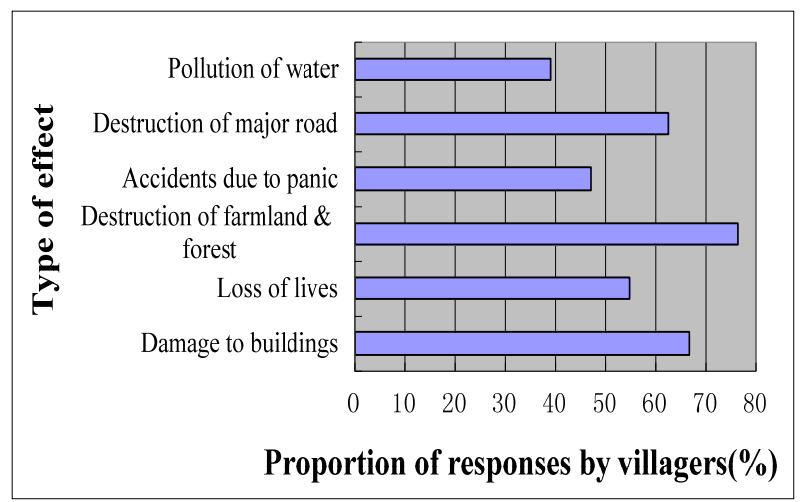

Fig. 5. Respondent's perceived effects which impacted on their lives from geological hazards

The results (Fig. 5) demonstrated that most of the population considers that their possessions and services would be affected (houses, schools, water supply, road, crops etc). Respondents identified major impacts caused by the geological hazards as: destruction of farmland $\&$ forest $(76.4 \%, \mathrm{n}=195)$; damage to buildings $(66.7 \%$, $\mathrm{n}=170)$; destruction of major road $(62.7 \%, \mathrm{n}=160)$; loss 
of lives $(54.9 \%, \mathrm{n}=140)$; accidents due to panic $(47.1 \%$, $\mathrm{n}=120)$ and; pollution of water $(39.2 \%, \mathrm{n}=100)$.

\subsection{Hazard information}

Effective disaster risk management depends upon a series of related actions and the means to engage the informed participation of all stakeholders. Exchange of information and communication practices play key roles in the realization of these activities. Several survey items were designed to assess the amount of information that residents have on the geological hazards they could face, and to determine the most common sources from which they had received this information. As the data in Fig. 6 shows, $65.9 \%$ of participants said they had received "insufficient" or "very little" information about the effects of a potential occurrence of the hazards, with very few people saying that they felt they had received enough information.

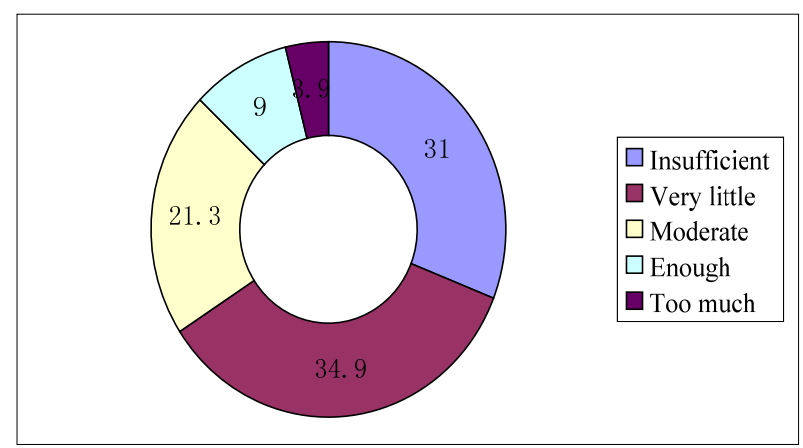

Fig. 6. Amount of information received regarding potential occurrence of geological hazards (\%)

Participants were then asked to indicate the sources from which they received the majority of their information about risks (Table 1). The results showed the most common methods of receiving hazard information. The respondents tended to choose interesting and vivid ways to get disaster knowledge, and publicity and education of geological hazards knowledge played an important role in risk communication. It indicated that $70.6 \% \quad(n=180)$ acquired the knowledge of geological hazards by the mass media (TV, broadcast, radio, newspaper, etc.); $60.7 \%(n=155)$ was informed by an elderly person in the village; with very few people $(11.8 \%, \mathrm{n}=30)$ acquired the information from Internet.
Table 1 The origin that people acquire the information of the prevention of geological hazards

\begin{tabular}{lc}
\hline Items & $\begin{array}{c}\text { Percentage } \\
(\%)\end{array}$ \\
\hline $\begin{array}{l}\text { 1. Pamphlets, leaflets, and posters on geological } \\
\text { hazards which distributed by local government }\end{array}$ & 50.2 \\
2. Disaster prevention education and emergency & \\
drill which be held in their villages & 43.1 \\
3.Village cadre, part-time geological hazards & \\
monitor in the village & 62.7 \\
4. TV, broadcast, radio, newspaper, etc. & 70.6 \\
5. School education & 23.5 \\
6. Acquaintance, especially elderly person in the & 60.7 \\
village & 19.6 \\
7. Research Institute & 27.5 \\
8. Self experience & 11.8 \\
9. Internet &
\end{tabular}

In the choice of platforms, the results indicated that mass media was the best means of informing the population of a looming crisis. It seemed that word of mouth also was a widespread means of communication of disaster information, while village cadre, geological hazards monitors and acquaintances were commonly mentioned sources. Comparatively speaking, as an important place for popularizing the education, the school did not play an important role in disaster reduction education, the reason might be the lack of corresponding teachers in mountainous areas, and need to strengthen the faculty in the future.

\subsection{Protective behavior}

The public awareness of disasters is a state of mind after people's processing information and knowledge of disasters and it will directly influence their attitudes and behavioral tendencies. And disaster preparedness is an essential element of the disaster management program. Each type of geological disaster requires clean-up and recovery. The period after a disaster is often very difficult for families, at times as devastating as the disaster itself. Families which are prepared ahead of time can reduce the fear, confusion and losses that come with disaster. They can be ready to evacuate their homes, know what to expect in public shelters and how to provide basic first aid. And be better able to cope with the disaster and recover from it more quickly.

In order to evaluate respondent's knowledge on preparing for hazards, we developed a number of questions which consisted of fourteen items (see Table 
2), inquiring about the adoption of different behaviors to reduce the impact of a crisis. The questionnaire was introduced with a sentence inviting respondents to think about a possible future geological hazard. Respondents were asked to indicate whether or not they had adopted each of the presented behaviors.

\section{Table 2 Protective behaviors: items}

\begin{tabular}{|c|c|}
\hline Items & $\begin{array}{l}\text { Percentage } \\
(\%)\end{array}$ \\
\hline $\begin{array}{l}\text { 1. Learn which disasters are possible where you } \\
\text { live and how these disasters might affect your } \\
\text { family. }\end{array}$ & 30.6 \\
\hline $\begin{array}{l}\text { 2. Keep a readily available list of emergency } \\
\text { phone number(doctor, work, school, relatives) }\end{array}$ & 33.3 \\
\hline $\begin{array}{l}\text { 3. Learn about your village's warning signals, what } \\
\text { they sound like, what they mean and what actions } \\
\text { you should take when they are activated }\end{array}$ & 23.1 \\
\hline 4. Attend a basic first- & 15.7 \\
\hline $\begin{array}{l}\text { 5. Develop a family preparedness plan which be } \\
\text { known to all family members. }\end{array}$ & 24.3 \\
\hline $\begin{array}{l}\text { 6. Ask someone (local government, relatives, etc.) } \\
\text { information about what to do in case of emergency }\end{array}$ & 17.3 \\
\hline $\begin{array}{l}\text { 7. Review possible evacuation procedures with } \\
\text { your family if you had to evacuate }\end{array}$ & 46.3 \\
\hline $\begin{array}{l}\text { 8. Store water in plastic containers such as soft } \\
\text { drink bottles }\end{array}$ & 32 \\
\hline $\begin{array}{l}\text { 9. Store at least a } 3 \text {-day supply of non-perishable } \\
\text { food. }\end{array}$ & 41 . \\
\hline $\begin{array}{l}\text { 10. Keep a working flashlight and extra batteries } \\
\text { operated radio in a convenient place known to all } \\
\text { family members }\end{array}$ & 47.8 \\
\hline oortant objects in a safe place & 40 \\
\hline $\begin{array}{l}\text { 12. Store at least one complete change of clothing } \\
\text { and footwear per person }\end{array}$ & 34. \\
\hline 13. Make some changes to home & 14.9 \\
\hline $\begin{array}{l}\text { 14. Purchase any kind of insurance against } \\
\text { geological disasters }\end{array}$ & 3 \\
\hline
\end{tabular}

Table 2 depicted the frequencies of specific protective behaviors adopted by participants in order to prepare for possible future geological hazards. The behavior that was more likely to be adopted by respondents was "Keep a working flashlight and extra batteries operated radio in a convenient place known to all family members", (47.8\%, $\mathrm{n}=122)$, followed by "Review possible evacuation procedures with your family if you had to evacuate"' $(46.3 \%, n=118)$ and "Store at least a 3-day supply of non-perishable food.' (41.6\%, n=106). "Make changes to the home", is the less diffused behavior, with only $14.9 \%$ of the respondents adopting this strategy. The mean number of adopted behaviors was 4.35 (Std. Deviation=2.61, Min=0, Max=10).About twenty percent of the respondents adopted seven or more than seven behaviors, and $32.5 \%$ of the participants adopted two or less behaviors. The results showed that the residents' awareness of geological disaster risks was generally poor. Even in villages where disasters had occurred relatively frequently in the past, the public had often failed to demand the most rudimentary protection. The development of increased public awareness about geological hazards and the understanding of disaster risks are vital elements in any comprehensive strategy for disaster reduction. Public awareness should be conducted through all possible means, including in schools, in particular through the

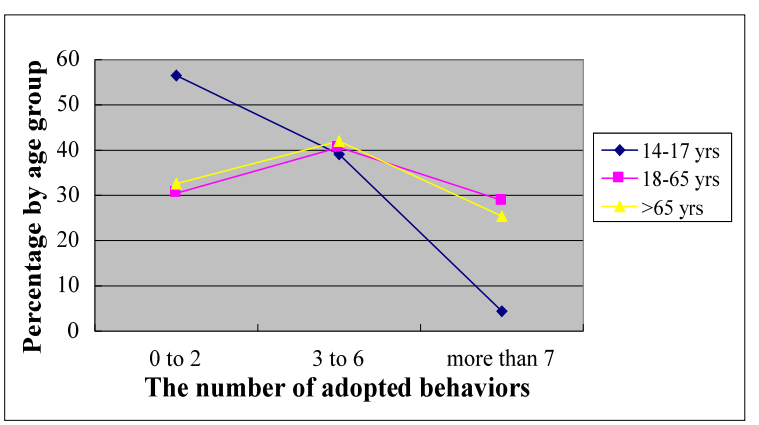

Fig. 7. The number of respondents adopted behaviors by different age groups.

media and other official, public, professional and commercial means, at all levels of society.

On exploring the number of adopted behaviors by age (Fig. 7), Chi-square values $\left(\mathrm{X}^{2}=50.525, \mathrm{p}=0.002\right)$, emphasize the differences in preferred protective behaviors between different age groups. It was revealed that most of the younger generation was inadequately prepared for the impending disaster in normal. An important way to deal with them is to strengthen public education on disaster prevention, while the younger have no strong awareness of disaster prevention.

\subsection{Risk Perception of geological hazard}

The risk perception category contained questions that addressed the characteristics of the geological disaster (i.e. the landslide). The items used in the questionnaire and their key terms are listed in Table 3. Its required respondents to make risk perception judgments regarding the likelihood that a geological hazard would 
occur in their villages in future, the clearness of know the mitigation actions that their can adopt, the severity of consequences that such an geological hazard eruption would cause for their lives, how serious the effects of a geological hazard eruption might be for themselves and their families, and how much they worry about a potential geological hazard. All ratings were made on a 5 point scale, with higher numbers indicating greater likelihood, severity of consequences, and worry. The mean ratings of each item (with $95 \%$ confidence intervals) were also presented in Table 3.

As shown in Table 3, on the first set of question, the mean score was 3.29 (S.D. $=1.08$ ) out of a total of 5 (1=likelihood very small; $5=$ likelihood very large). This indicated that villagers on average felt that a geological hazard would likely occur at their hometown in the following five years. The mean score of "Know mitigation actions" was 2.70 (S.D. $=1.38$ ), which meant that villagers on average did not know the mitigation action clearly during a geological hazard eruption. In the third item, the mean score was 2.66 (S.D. $=1.16$ ), which showed that most of respondents did not think they had the capable of controlling the hazard to avoid a huge loss once a geological hazard occurred. In the fourth item, the mean score was 3.22 (S.D. =1.02), which indicated that it would threaten villagers' life serious once a geological hazard occurred. In the fifth and sixth item, the mean score was 3.17 and 3.38 respective, which meant that if there was a geological hazard eruption, the villagers would be affected the quality of life and/or be brought financial loss serious. And to the last question, the mean score was 3.34 (S.D.

Table 3. Risk perception of geological hazard and respondents' age: items

\begin{tabular}{|c|c|c|c|c|}
\hline Key term & Description of Scale & Age group & Mean & Standard Deviation \\
\hline \multirow{4}{*}{ Likelihood } & \multirow{4}{*}{$\begin{array}{l}\text { In the village in which you live, how likely is it } \\
\text { that a geological hazard will occur in the following } \\
\text { five years? }\end{array}$} & All & 3.29 & 1.08 \\
\hline & & 14 to 17 years old & 3.09 & 1.35 \\
\hline & & 18 to 65 years old & 3.35 & 1.06 \\
\hline & & older than 65 & 3.11 & 1.02 \\
\hline \multirow{4}{*}{$\begin{array}{l}\text { Know } \\
\text { mitigation } \\
\text { actions }\end{array}$} & \multirow{4}{*}{$\begin{array}{l}\text { If there is a geological hazard eruption, do you } \\
\text { know the mitigation actions you can adopt clearly? }\end{array}$} & All & 2.70 & 1.38 \\
\hline & & 14 to 17 years old & 2.91 & 1.41 \\
\hline & & 18 to 65 years old & 2.64 & 1.35 \\
\hline & & older than 65 & 2.89 & 1.53 \\
\hline \multirow{5}{*}{$\begin{array}{l}\text { Able } \\
\text { control }\end{array}$} & \multirow{4}{*}{$\begin{array}{l}\text { If there is a geological hazard eruption, do you } \\
\text { think that you are capable of controlling the hazard } \\
\text { to avoid a huge loss? }\end{array}$} & All & 2.66 & 1.16 \\
\hline & & 14 to 17 years old & 3.00 & 1.21 \\
\hline & & 18 to 65 years old & 2.59 & 1.11 \\
\hline & & older than 65 & 2.83 & 1.22 \\
\hline & \multirow{4}{*}{$\begin{array}{l}\text { If there is a geological hazard eruption, to what } \\
\text { extent does the hazard threaten your life? }\end{array}$} & All & 3.22 & 1.02 \\
\hline \multirow{3}{*}{ Threaten life } & & 14 to 17 years old & 3.04 & 1.30 \\
\hline & & 18 to 65 years old & 3.26 & .96 \\
\hline & & older than 65 & 3.14 & 1.19 \\
\hline \multirow{4}{*}{$\begin{array}{l}\text { Affect } \\
\text { quality }\end{array}$} & \multirow{4}{*}{$\begin{array}{l}\text { If there is a geological hazard eruption, to what } \\
\text { extent does the hazard affect the quality of your } \\
\text { life? }\end{array}$} & All & 3.17 & .98 \\
\hline & & 14 to 17 years old & 2.87 & 1.10 \\
\hline & & 18 to 65 years old & 3.21 & .96 \\
\hline & & older than 65 & 3.14 & 1.03 \\
\hline \multirow{4}{*}{ Financial loss } & \multirow{4}{*}{$\begin{array}{l}\text { If there is a geological hazard eruption, to what } \\
\text { extent does the hazard bring you financial loss? }\end{array}$} & All & 3.38 & 1.13 \\
\hline & & 14 to 17 years old & 3.30 & 1.06 \\
\hline & & 18 to 65 years old & 3.40 & 1.09 \\
\hline & & older than 65 & 3.29 & 1.41 \\
\hline \multirow{4}{*}{ Dread } & \multirow{4}{*}{$\begin{array}{l}\text { In general, how afraid are you of a geological } \\
\text { hazard? }\end{array}$} & All & 3.34 & 1.10 \\
\hline & & 14 to 17 years old & 2.83 & 1.23 \\
\hline & & 18 to 65 years old & 3.43 & 1.07 \\
\hline & & older than 65 & 3.20 & 1.13 \\
\hline
\end{tabular}

Note: Ratings were made on a Likert 5 point scale, with higher numbers indicating higher levels of likelihood, severity, worry and self-efficacy. 
$=1.10$ ), which showed that villagers on average were afraid of a geological hazard in general.

In order to determine whether age played a significant role in determining various aspects of risk perception, a series of comparisons were made among four groups (All, minors, adults, elderly group). The results of those analyses which were statistically significant also were presented in Table 3. There were no clear patterns in the results of these analyses.

\subsection{Correlational analysis}

In order to determine whether the measures of Sociodemographic and experiential characteristics used in the study were related to the residents' perceptions of risk, a series of correlations were calculated among these measures (see table 4).

As the data in Table 4 illustrated, in general, the correlation matrix showed that when the values of know mitigation actions, and able to control increased, the values of "Threaten life", "Affect life quality", "Financial loss", and "Dread" decreased. In addition, "Know mitigation actions" and "Able to control" were positively correlated with each other.
Secondly, as regards the relationship between education and the other study variables, we found that the value of "Education" was positively correlated with the value of "Know mitigation actions" and "Able to control" $(\mathrm{r}=0.696$ and 0.616 respective; $\mathrm{p}<0.01)$, and negatively correlated with the value of "Likelihood", "Threaten life", "Affect life quality", "Financial loss" and "Dread" $(\mathrm{r}=-0.544,-0.448,-0.372,-0.437$ respective; $\mathrm{p}<0.01)$.

Finally, other significant correlations between the sociodemographic and experiential variables examined in the present study showed that having taken part in disaster drill activities and personal disaster experience was positively correlated with having received information about the geological hazards $(\mathrm{r}=0.610$ and 0.468 respective, $\mathrm{p}<0.01$ ).

The above results indicate that introducing disaster risk reduction strategies through the educational system is one of the key successful interventions. Disaster preparedness, prevention and response should be part of the general education curriculum. People in schools, villages and workplaces should be continuously informed and trained to cope with geological hazards. Training session in risk reduction for geological hazards

Table 4. Correlations between study variables $(\mathrm{N}=255)$.

\begin{tabular}{|c|c|c|c|c|c|c|c|c|c|c|c|c|c|}
\hline Variable & 1 & 2 & 3 & 4 & 5 & 6 & 7 & 8 & 9 & 10 & 11 & 12 & 13 \\
\hline \multicolumn{14}{|c|}{ Socio-demographic and experiential characteristics } \\
\hline 1. Gender & 1 & & & & & & & & & & & & \\
\hline 2. Age group & -.086 & 1 & & & & & & & & & & & \\
\hline 3. Education & $.187 * *$ & -.103 & 1 & & & & & & & & & & \\
\hline $\begin{array}{l}\text { 4.Personal disaster } \\
\text { experience }\end{array}$ & -.021 & -.020 & .101 & 1 & & & & & & & & & \\
\hline $\begin{array}{l}\text { 5.Received risk } \\
\text { information }\end{array}$ & -.022 & -.051 & .072 & $.610 * *$ & 1 & & & & & & & & \\
\hline $\begin{array}{l}\text { 6.Participate } \\
\text { disaster drill }\end{array}$ & .007 & -.102 & $-.129 *$ & $.223 * *$ & $.468 * *$ & 1 & & & & & & & \\
\hline \multicolumn{14}{|c|}{ Risk perception of geological hazards } \\
\hline 7.Likelihood & .066 & -.011 & $-.544 * *$ & -.098 & -.016 & $.335 * *$ & 1 & & & & & & \\
\hline $\begin{array}{l}8 . \text { Know } \\
\text { mitigation actions }\end{array}$ & $-.139 *$ & .009 & $.696^{* *}$ & .097 & .028 & $-.247 * *$ & $-.816 * *$ & 1 & & & & & \\
\hline 9.Able to control & -.101 & -.014 & $.616^{* *}$ & .073 & .019 & $-.274 * *$ & $-.882 * *$ & $.885 * *$ & 1 & & & & \\
\hline 10.Threaten life & .073 & .011 & $-.448 * *$ & .019 & -.048 & $.209 * *$ & $.722 * *$ & $-.613 * *$ & $-.690 * *$ & 1 & & & \\
\hline $\begin{array}{l}\text { 11.Affect life } \\
\text { quality }\end{array}$ & .036 & .050 & $-.442 * *$ & -.017 & -.030 & $.233 * *$ & $.637 * *$ & $-.532 * *$ & $-.608 * *$ & $.744 * *$ & 1 & & \\
\hline 12.Financial loss & .060 & -.011 & $-.372 * *$ & .005 & -.094 & $.193 * *$ & $.583 * *$ & $-.506 * *$ & $-.572 * *$ & $.744 * *$ & $.588 * *$ & 1 & \\
\hline 13.Dread & $.169 * *$ & .052 & $-.437 * *$ & -.009 & -.012 & $.304^{* *}$ & $.746 * *$ & $-.662 * *$ & $-.721 * *$ & $.615 * *$ & $.494 * *$ & $.509 * *$ & 1 \\
\hline
\end{tabular}


(i.e. the mudflow) complete with simulation exercises and concrete preparation actions should be conducted in mountainous areas.

\section{Conclusion}

The present study aimed to investigate disaster preparedness and risk perception among a group of people living in villages located in mountainous areas in Qingyuan County, particularly exposed to the risk of abrupt geological hazards (i.e. the landslides). The results showed as following:

(1) The natural hazards in Qingyuan County were foremost in the minds of residents in the following descending order: Landslides, Mudflows, Torrents, Droughts, Rock fall and Earthquakes.

(2) Respondents identified major impacts caused by the geological hazards as descending order: destruction of farmland \& forest, damage to buildings, destruction of major road, Loss of lives, accidents due to panic and pollution of water.

(3) Most of participants had received "insufficient" or "very little" information about the effects of a potential occurrence of the hazards. Mass media and word of mouth were the best means of informing the population of a looming crisis.

(4) The mean number of adopted behaviors was 4.35 out of 14, which showed that the residents' preparedness of geological disaster was poor.

(5) Villagers on average felt that a geological hazard would likely occur at their hometown in the following five years, and did not know the mitigation action clearly during a geological hazard eruption. They could not control the hazard to avoid a huge loss and would threaten villagers' life serious once a geological hazard occurred. The villagers would be affected the quality of life and/or be brought financial loss serious, and were afraid of a geological hazard in general. There were no clear patterns in the results as age difference.

(6) The Variable "Know mitigation actions" and "Able to control" were positively correlated with "Threaten life", "Affect life quality", "Financial loss", and "dread decreased". "Know mitigation actions" was positively correlated with "Able to control". The Variable "education" was positively correlated with "Know mitigation actions" and
"Able to control", and negatively correlated with "Likelihood", "Threaten life", "Affect life quality", "Financial loss" and "Dread". The Variable "Participate disaster drill" and "Personal disaster experience" was positively correlated with "Received risk information".

\section{Acknowledgements}

This material is based upon work funded by Zhejiang Provincial Natural Science Foundation of China under Grant No. Y5110022

\section{References}

1. China Meteorological Administration. Yearbook of Meteorological Disaster in China (2005-2009). Beijing: Meteorological Press, 2005-2009. (in Chinese)

2. Janis, I. and L. Mann. (1977) Decision Making: A Psychological Analysis of Conflict, Choice and Commitment. New York: Free Press.

3. Slovic, P., ed. (2000). The Perception of Risk. London: Earthscan.

4. Chan, J. C. L. and K. S. Liu, 2004: Global warming and western North Pacific typhoon activity from an observational perspective. J. Climate, 17, PP. 45904602.

5. F. Barberi, M.S. Davis b, R. Isaia, R. Nave, T. Ricci. Volcanic risk perception in the Vesuvius population. Journal of Volcanology and Geothermal Research 172 (2008), PP. 244-258.

6. Mileti, D. (1993) "Communicating Public Earthquake Risk Information." In Prediction and Perception of Natural Hazards, J. Nemec, J. Nigg, and F. Siccardi (eds). Boston: Kluwer Academic Publishers.

7. Lindell, M. and R. Perry. (1993) "Risk Area Residents" Changing Perceptions of Volcano Hazard at Mt. St. Helens." In Prediction and Perception of Natural Hazards, J. Nemec, J. Nigg, and F. Siccardi (eds). Boston: Kluwer Academic Publishers.

8. Kates, R.W., 1971. Natural hazard in human ecological perspective: hypotheses and models. Econ. Geogr. 47 (3), PP.438-451.

9. Lindell, M.K. and Perry, R.W. Household adjustment to earthquake Hazard: A review of research, Environment and Behavior, 2000, 32 (4), PP. 461-501.

10. Zhouqi, Yuyaochuang. Study on the natural disaster perception of village in a mountainous area-Take Shangbaiyun Village, Taibai County, as a example. Journal of Mountain Science, 2008,26(5):571 576. (in Chinese).

11. SUN Lili, CHEN Ailian, WANG Xiangming. Factors analysis of influence on refuge behavior against typhoon 
PAN Anping

disaster in mountainous area. Journal of Natural Disasters, 2010, 19(6):165-170 (in Chinese).

Published by Atlantis Press Copyright: the authors

55 